12 neural tube defects among the 192 infants born to the mothers in the untreated group.

More recently, Smithells and his colleagues have extended their study to include more than 1,000 women with a history of neural-tube defective births, self-selected into two roughly equal groups. They report that the incidence of a second neural-tube defective birth was 0.6 per cent (based on three births) in the group of supplemented mothers, but 4.7 per cent among the children born to untreated mothers.

This seven-fold difference apart, the bearing of the Smithells study on the question of whether vitamins including folic acid were an effective prophylactic of the recurrence of neural tube defects is disputed. First, and most seriously, because the study group is self-selected, the results may be seriously biased, and in the direction reported. For if mothers of higher social class are less likely to decline a course of vitamin supplementation, and are inherently less at risk of producing neural-tube defective children, the results of the trial may partially be explained.

On this point, Smithells argues that the data now accumulated include 44 women with more than one neural-tube defective child who have agreed to accept vitamin supplements and 52 women with two or more defective children who had not joined the trial. (The first group produced one defective child, the second five.) To Smithells, however, the significance of this development is to give the lie to the criticism of his earlier work that mothers accepting vitamin supplementation select themselves in consonance with their tendency to produce neural-tube defective children.

Another difficulty is that the catchment area from which the participants in this study have been drawn includes Ulster, where the natural incidence is large, and the south-east of England, where it is small. Recruitment to the programme of vitamin supplementation seems indeed to have been more successful in the south-east of England ( 50 per cent) than in Ulster ( 25 per cent).

It seems also to be agreed that the Smithells trial does not point unambiguously to folic acid rather than some other components of the vitamin preparation used as the putatively effective prophylactic. The preparation used (obtainable in the United Kingdom only on prescription) is manufactured by Beecham Pharmaceuticals Limited, is known as "Pregnavite Forte F" and contains a mixture of vitamins (including ascorbic acid) as well as iron and calcium salts.

During the past year, the Medico-Social Research Board in the Republic of Ireland has mounted a trial initially intended to throw light on this point. With the collaboration of several Dublin maternity hospitals, the board is sponsoring a trial in which three groups of mothers with a history of neural-tube defective children are being offered Pregnavite Forte F, Pregnavite Forte (without folic acid) and folic acid alone. Dr Geoffrey Dean, the board's director, said on the telephone last week that "everybody is convinced that the Smithells theory is not proven". The Dublin study also suffers from the defect that there is no objectively chosen control group with which the effects of vitamin supplementation can be compared.

In Dublin there is some resentment that in the past few months Beechams (which had been supplying the vitamin preparations free of charge) has written to say that it cannot continue this provision (see box). Dr Dean hopes that, nevertheless, it should be possible to recruit enough mothers with a history of neuraltube defective children for a significant result to be available within two years.

In Britain, the interest of the Department of Health in 1980 prompted a seminar in December of that year at which several interested and disinterested parties discussed the conduct of a clinical trial intended to yield significant and decisive results, in which the participants would again be mothers with a history of neuraltube defective births.

\section{Beecham's supplement}

The decision of Beecham Pharmaceuticals Lid to go back on its earlier agreement to supply "Pregnavite Forte F" for the Irish trial free of charge, which has caused some ill-feeling in Dublin, is said to have been prompted by the company's internal ethical committee. According to $\mathrm{Mr}$ J. B. Diamond, chairman of Beecham (UK) Ltd, the ethical committee includes "secretaries and people like that".

Mr Diamond explained that his company had supplied material for the trials carried out by Professor R.W. Smithells and his associates over a period of some years, and also for the Irish trials. But "when it became clear that the [proposed] trials raised great ethical problems", the committee had decided that it would be wrong for Beecham to supply a placebo for the MRC trial and, by extension, to supply a vitamin supplement containing folic acid for other trials.

On the question of the safety of folic acid as a dietary supplement, $\mathrm{Mr}$ Diamond said on the telephone this week that the company had been marketing Pregnavite Forte $F$ since 1952, before the licensing of drugs became the statutory responsibility of the Department of Health on the advice of the Committee on the Safety of Medicines. As such, the product has a licence "as of right", which may nevertheless be called in question whenever the committee considers that there has been a significant change of usage.
The most controversial feature of this proposal is that there should be a true control group - a group of women selected double-blind to whom only a placebo should be administered. Three other groups would receive respectively a multivitamin preparation, a multivitamin preparation with folic acid, and folic acid without other vitamins (but with minerals). The folic acid dose would be $4 \mathrm{mg}$ a day, roughly ten times the amount of folic acid in the Beechams preparation.

The Medical Research Council, which apparently has indications that 20 per cent of the 3,000 women it would need in a full trail are willing to take part, has run into the following snags.

- Several Members of Parliament have been asking questions of the Department of Health about the conduct of the trials. They include $\mathrm{Mr}$ Roger Thomas, Mrs Gwyneth Dunwoodie and Mr Leo Abse. The common thread in their questioning has been to ask why their constituents should be denied an apparently effective treatment.

- On some legal views, informed consent by participants in the trial would not necessarily absolve the physicians concerned from legal action of the birth of damaged children.

- The amounts of folic acid planned for the MRC trials (ten times the amounts included in Pregnavite Forte F) have suggested to some that the procedure could be dangerous. While there is no evidence one way or the other, prudence dictates caution.

- If trials should show that folic acid, alone or in conjunction with other vitamins, should be effective at preventing recurrences of neural-tube defective births, it is by no means clear how that knowledge would be used for the prevention of defective first births.

In the circumstances, the opinion about the proposed trials of scientists working in the field understandably ranges over the whole spectrum. Some hold that the Smithells case, if not fully proven, is sufficiently convincing to make the use of a placebo in the trials unethical. Others would avoid the uncertainties occasioned by the choice of a dose of $4 \mathrm{mg}$ a day by arguing that the amounts used should be smaller until animal tests have been carried out.

On the other hand, there are many who hold that the Smithells investigations raise so many more questions than they answer that a trial with placebo is probably necessary. The ideal would obviously be to ring the changes on all the vitamins administered, but this is probably unpracticable in the short term, which is why some argue for detailed physiological investigations of smaller numbers of women at risk.

Professor R.W. Smithells himself hopes that the Medical Research Council "will decide to carry out a trial" at its next meeting on 7 December. 